\title{
The Economics of Information, Deep Capture, and the Obesity Debate
}

\author{
Trenton G. Smith and Attila Tasnádi
}

Address for correspondence:

Trent Smith

Department of Economics

University of Otago

PO Box 56

Dunedin

NEW ZEALAND

Email: trent.smith@otago.ac.nz

Telephone: 6434794596 


\title{
The Economics of Information, Deep Capture, and the Obesity Debate
}

\author{
Trenton G. Smith ${ }^{1}$ and Attila Tasnádi ${ }^{2}$
}

8 November 2013

${ }^{1}$ Corresponding author. University of Otago, Department of Economics, PO Box 56, Dunedin 9054, New Zealand. Tel +64 3479 4596, e-mail trent.smith@otago.ac.nz.

${ }^{2}$ Corvinus University of Budapest and MTA-BCE "Lendület" Strategic Interactions Research Group 
In theory, everybody buys the best and cheapest commodities offered him on the market. In practice, if everyone went around pricing, and chemically testing before purchasing, the dozens of soaps or fabrics or brands of bread which are for sale, economic life would become hopelessly jammed. To avoid such confusion, society consents to have its choice narrowed to ideas and objects brought to its attention through propaganda of all kinds. There is consequently a vast and continuous effort going on to capture our minds in the interest of some policy or commodity or idea.

-Edward L. Bernays, Propaganda (1928, p. 11)

The increasing dominance of convenient, inexpensive, aggressively-advertised brandname fast foods and snack foods in the American marketplace has largely coincided with the timing of the obesity epidemic (Chou et al., 2004), leading some to blame the food industry for creating an "obesigenic" environment in which overeating has become the norm (Brownell and Horgen, 2004). While it is easy to dismiss such claims as hyperbolic and undeserving of serious economic analysis, this article considers the conditions under which such claims (e.g., that supply-side factors generate an equilibrium in which the nutritional quality of food is in some sense lower than the social optimum) might be expected to be true. In this article we argue that the presence of search costs-and, critically, the endogeneity of consumer beliefs - can make it possible for foods low in nutritional quality to dominate the market. We demonstrate the empirical relevance of the phenomenon - in which firms expend costly effort to influence consumer beliefs - with a discussion of the food industry response to the obesity epidemic.

To the extent that the producer of a branded, nationally advertised retail food product actually chooses nutritional quality, the decision necessarily takes place within the context of a modern marketing plan. Within such a plan, nutritional quality is jointly determined with decisions about quality and type of ingredients, processing technologies, and the timing and method of distribution, all of which will have direct impacts on profitability. But nutritional quality will also, ceteris paribus, affect profitability 
indirectly via demand-side effects: in particular, higher (perceived) quality might be expected to increase demand

Of course, if consumers were fully informed about quality, we might expect competitive markets to ensure that these various trade-offs are made in an efficient manner, and that the level of quality realized in the marketplace simply reflects the natural interaction of consumer demand with evolving food production technologies. But for the ordinary consumer, who may be unschooled in nutrition science and know little of industrial food production methods, full information is certainly an heroic assumption. This fact has long been acknowledged, and is the standard justification for food safety regulations and food labeling requirements and restrictions (Darby and Karni, 1973; Teisl and Roe, 1998; Smith et al., 2011).

Regulators such as the U.S. Department of Agriculture (USDA) and the Food and Drug Administration (FDA), however, face a daunting task: balancing the competing interests of consumer and producer when nutrition science is complex, evolving, and sometimes controversial, and production costs (not to mention demand-side effects) associated with new regulations can be difficult to estimate. Given these uncertainties, large producers (or groups of producers) can naturally be expected to make costly investments in participation in the rule-making process, actions that can reasonably be viewed as a form of rent-seeking.

Stigler (1971) wrote of the corrupting effect of political interference on industry regulation, a phenomenon now commonly referred to as "regulatory capture." His stylized economic model, in which regulations are bought and sold on the open market, may have been deeply cynical, but its empirical validity seemed strong enough that it has spawned new theories of regulatory design aimed at minimizing the problem (Croley, 2007). What Stigler failed to note, however, was that his logic - that an industry will attempt to influence powerful government institutions that affect its bottom line-applies equally to any institution that holds such power. This larger phenomenon, in which industry attempts to influence not only its regulator, but also (perhaps) politicians, celebrity spokespeople, the media, education, and even academic research — with the aim, 
ultimately, of influencing the broader public - has been dubbed "deep capture," and like Stigler's more limited theory, appears in many cases to have empirical validity (Hanson and Yosifon, 2003; Benforado et al., 2004; Yosifon, 2006). Viewed in light of modern information theory, the problem of nutritional quality in manufactured foods is in essence an equilibrium selection problem, in which profitability is a function of consumer perceptions and beliefs about nutrition. It is interesting to consider the extent to which the "deep capture" phenomenon might be affecting these beliefs. After introducing the problem and laying a theoretical foundation, ${ }^{3}$ this article considers examples of food industry practices consistent with deep capture theory, along with the possibility that public perceptions about the cause(s) of the obesity epidemic have been influenced by these practices.

\section{A Model of Costly Search with Endogenous Information}

The theory of regulatory capture (further developed in the years since Stigler's 1971 article; see Bó (2006) for a review) has tended to emphasize the principal-agent-agent problem in which government is unable to fully observe the actions of both the regulator and the firm (Tirole, 1986; Laffont and Tirole, 1993). Because the target in deep capture is the consumer (or, more broadly, the public), we are inclined to view (and model) the phenomenon as a hidden quality problem. As noted above, the mechanisms by which deep capture is achieved may include regulatory capture, but there are many other institutions with the power to influence the public. Rather than modeling the firm's allocation of effort across these mechanisms (a task we leave for future research), we have chosen to emphasize the interaction between profit-maximizing firms and rational (but partially uninformed) consumers. We do this in part because the existing literature on deep capture - which has appeared primarily in law journals — relies heavily on a view of consumer behavior drawn from social psychology (Hanson and Yosifon, 2003, 2004). In this view, deep capture is made possible by assuming that consumers are susceptible to

\footnotetext{
${ }^{3}$ To the best of our knowledge, ours is the first formal model of deep capture.
} 
what is called the fundamental attribution error - a form of self-deception in which individuals are unaware that exterior forces have influenced their actions. While acknowledging the large and varied body of empirical research in psychology supporting this view, our aim is to demonstrate the feasibility of deep capture in a parsimonious manner, without resorting to psychological constraints.

The stylized model of modern food markets we describe here relies on three key observations:

1. The market can be viewed as divided broadly among two types of retail food products: those that are industrially produced, and those that are traditionally produced. Industrial foods are efficiently produced on a large scale, are promoted and sold nationally or internationally, and are generally agreed by health professionals to be of lower nutritional quality, on average, compared to traditionally produced foods (Kotz and Story, 1994; Isganaitis and Lustig, 2005; Batada et al., 2008; Smith et al., 2011).

2. There is sufficient market concentration in industrial foods to make investments in deep capture profitable. That is to say, there exist producers of mass-marketed foods whose market share is large enough to justify (individual or in coalition with other large producers) not just brand-name promotion but also costly attempts to influence institutions that affect the size of the market for all (industrially-produced) products within a given class of food products. Examples of such activity are not hard to find: The National Soft Drink Association (now the American Beverage Association), for example, once provided educational materials to schools that informed children about the nutritional value of the "needed liquids and energy" in soft drinks and the nutritional equivalence of the sugars found in these products to the sugars found in fruit (Jacobson, 2005). Food companies have also invested heavily in nutrition science, by funding not just independent studies but even scientific societies such as the American Diabetes Association-whose corporate sponsors include Kraft Foods, J.M. Smucker, General Mills, H.J. Heinz, and Cadbury Schweppes (Simon, 2006). In the model 
we present below we abstract from the strategic coordination problem that arises when more than one firm has market power and assume a single seller acts in the interest of industrial producers. For traditional foods we assume efficient scale to be sufficiently small that such collective action is not feasible.

3. Consumers have an imperfect ability to observe product quality, and must rely on a combination of costly search activity and post-consumption experience to make judgments about the quality of a specific producer's food product. Given the fact that even scientists cannot agree on the precise causes of (or cures for) the obesity epidemic (Smith, 2012), it does not seem unreasonable to posit that consumer knowledge about the health consequences of consuming particular processed food products will (in the absence of costly effort) necessarily be incomplete.

\section{The Model}

We begin by positing a consumer search setting consistent with the model introduced by Weitzman (1979), as follows: The consumer is faced with a choice of $n$ products, one of which is of low quality $(L)$ and the rest of which are of high quality $(H)$. The consumer must pay search cost $c_{i}$-which we interpret as any sunk cost that does not accrue to the seller, such as travel cost or time spent finding or locating or researching a productbefore consuming a good of type $i, i \in\{L, H\}$. Good $L$ yields value $x_{L}$ with probability $p_{L}$ and zero with probability $\left(1-p_{L}\right)$. We allow for heterogeneity in consumer preferences with respect to products of type $H$ by assuming that consumers are distributed uniformly on the unit interval, such that for consumer $l, l \in[0,1]$ a given type- $H$ good yields value $x_{H}(l)=a+l b$ with probability $p_{H}$ and zero with probability $\left(1-p_{H}\right)$ where $b>0$ and $l$ is

the market share of the low-quality product. Note that linearity of $x_{H}(l)$ follows directly from the uniform distribution assumption, and $a$ and $b$ are arbitrary constants analogous to $x_{L}$.

In this setting, Weitzman (1979) shows that the consumer's decision as to which product to choose (i.e., for which product, if any, he will choose to pay the search cost in 
order to discover its true value) is determined entirely by his reservation price, defined as the maximum price he would be willing to pay for the privilege of choosing a given product, if no other (yet-to-be-searched) products were available. In particular, the consumer will choose the product with the highest reservation price.

Assuming that high-quality and low-quality producers are both viable, the equation

$$
a+l b-\frac{c_{H}}{p_{H}}=x_{L}-\frac{c_{L}}{p_{L}} \geq 0
$$

specifying that the reservation prices for both types of product are the same, has a solution $l^{*} \in(0,1)$. We assume that the reservation price of the marginal consumer $l^{*}$ determines the equilibrium price of the products. Then

$$
l^{*}=\frac{1}{b}\left(x_{L}-a+\frac{c_{H}}{p_{H}}-\frac{c_{L}}{p_{L}}\right) .
$$

And (neglecting production costs), ${ }^{4}$ the low-quality producer's profit function is given by

$$
\pi_{L}=\frac{1}{b}\left(x_{L}-a+\frac{c_{H}}{p_{H}}-\frac{c_{L}}{p_{L}}\right)\left(x_{L}-\frac{c_{L}}{p_{L}}\right)
$$

Note that in equilibrium, profit is a function of the (exogenously given) parameters of the consumer's search problem. This allows us to investigate the implications of the introduction of technology that allows the low-quality producer (henceforth " $L$ ") to alter these parameters.

\section{The Comparative Statics of Equilibrium Selection}

Suppose, first of all, that $L$ seeks to maximize profit and is able to costlessly manipulate the parameters of the model. In which direction would he choose to move them? It is

\footnotetext{
${ }^{4}$ Given that we have assumed viability, production cost will only come into play at the margin when market share is affected. This assumption is thus qualitatively equivalent to assuming constant marginal cost.
} 
easy to show that in each case the marginal effect on profit is unambiguous, with $\frac{\partial \pi_{L}}{\partial c_{L}}<0$, $\frac{\partial \pi_{L}}{\partial c_{H}}>0, \frac{\partial \pi_{L}}{\partial x_{L}}>0, \frac{\partial \pi_{L}}{\partial a}<0, \frac{\partial \pi_{L}}{\partial b}<0, \frac{\partial \pi_{L}}{\partial p_{L}}>0$, and $\frac{\partial \pi_{L}}{\partial p_{H}}<0$. Also of interest is the special case in which the two types of firms share a common search cost $c$, for which it can be shown that $\frac{\partial \pi_{L}}{\partial c}>0$. The strictly monotonic marginal profits in each case imply that $L$ would pay to alter each parameter accordingly, assuming sufficiently cost-effective technology were available and legal or other barriers did not stand in the way. We briefly discuss the implications of each below.

\section{Search Costs: Promotion vs. Obfuscation}

First, $L$ can increase profits at the margin by decreasing $c_{L}$, the search cost faced by a consumer considering whether to purchase his product. This might be accomplished by providing product information via the media (e.g., advertising, op-ed pieces, press releases), or by making purchase convenient (e.g., by location of stores), or by lobbying for transparent quality standards that product $L$ satisfies.

When it comes to the high-quality competition, however, our model suggests $L$ should take the opposite view. Search $\operatorname{cost} c_{H}$ can, for instance, be increased (or maintained at high levels) by $L$ via active opposition to informative and credible thirdparty quality verification systems. But the absence of substantive oppositional promotion (i.e., costly actions that might serve to lower $c_{H}$ ) from the atomistic $H$-type producers can also be viewed as an important determinant of equilibrium search costs.

Perhaps a more ubiquitous form of obfuscation involves the case of common search costs $(c)$. Consider, for example the problem of ambiguous quality claims. Nutrition science is sufficiently esoteric for most consumers as to make seemingly substantive claims (e.g., "natural," "heart-healthy," "high in vitamins," "tested rBGH free") indistinguishable from similar-sounding non-substantive claims. Sorting out competing 
claims of this sort is costly for the consumer, and thus the use of non-substantive claims can be viewed as a form of obfuscation by $L$. This problem is thought to be widespread (Stivers, 2009), and is the reason regulations are often issued restricting the use of particular claims (Verbeke, 2005). Of course, our model suggests that $L$ may have incentive to work against the issuance of such regulations.

\section{Perceived Quality: Public Relations \& Quality Standards}

It is unsurprising that $L$ will benefit, all else equal, from higher perceived quality $\left(x_{L}\right)$ and a greater probability of satisfying his customers $\left(p_{L}\right)$ once they have made a purchase. Perceived quality can be influenced not just by advertising but indeed by all the tools of the modern public relations campaign: paid expert testimonials, industry-funded scientific research, newspaper op-eds, and fake grassroots organizations, to name a few.

Influencing the competition's perceived quality (i.e., parameters $x_{H}$ and $p_{H}$ ) might be difficult to achieve via the above-mentioned methods. But it is undoubtedly true that intervention in the regulatory process (e.g., by lobbying against quality standards or traceability requirements in order to foment a "lemons" collapse of quality competition) can affect equilibrium levels of quality observed in the marketplace. While we do not model this process directly, our results do provide some motivation for the posturing observed in recent debates such as the formulation of the 2000 organic standard in the U.S. (in which critics argued that the final rule was overly influenced by large industrialscale producers) (Salatin, 2007).

\section{Obesity: The Food Industry Perspective}

In sum, the model described above emphasizes that large industrial producers of food have incentive to invest in expansion of their market share, and the costly information problem faced by consumers suggests a number of levers by which such expansion might be accomplished. This is not to say that any one party is necessarily "to blame" for the poor nutritional outcomes (including obesity) that have come be associated with 
industrially processed foods; indeed, in our model firms are merely seeking to maximize profits to the best of their abilities, while consumers similarly make optimal choices for themselves, given the informational constraints they face. But nutritional quality in the marketplace is, nevertheless, one of many candidate causes of the obesity epidemic, and it seems reasonable to ask whether commercial interests have played a role in public perceptions of the problem.

There is considerable evidence that commercial food producers have in various ways worked to influence the powerful institutions suggested by Deep Capture theory: legislators, regulators such as the FDA and USDA, academic researchers, celebrity personalities, and even public schools. But as this evidence is readily available elsewhere (Benforado et al., 2004; Hanson and Yosifon, 2003; Iuliano, 2010; Simon, 2006; Smith et al., 2011), we will not attempt a comprehensive review here. Our aim is more limited: to identify and critique the industry response to concerns that processed foods might be causing obesity. The industry message is well-honed and can be summarized in three simple phrases: count calories, exercise more, and let consumers choose. These messages (which are evident in virtually every communication of industry spokespeople relating to obesity), each have the virtue of being logical and intuitive. Each, it can be argued, is also deeply misleading.

\section{Message 1: Count Calories}

It is often said that obesity is the result of energy imbalance. When calories taken in through the diet exceed calories expended via physical exercise, the argument goes, the body stores the excess as fat. This suggests that the obesity epidemic must have been caused by either an increase in caloric intake, or a decrease in physical exercise (or both); and, similarly, that if the obese wish to lose weight they can simply reverse the imbalance via some combination of reduced caloric intake and/or increase physical activity.

This "calories in/calories out" formulation is simple and intuitive, and has the advantage (for the industry) of implicitly supporting the claim that no food is fattening when eaten in moderation. There is, however, good evidence that some foods are more 
fattening than others, and that the difference has little to do with calories. A striking demonstration of this fact can be found in the experimental study of Granfeldt et al. (1991). Two groups of adult human subjects were fed meals (bread or pasta) made from precisely the same ingredients, so that calorie and carbohydrate content were identical. Over the next three hours, the subjects who had eaten the bread (but not those who had eaten the pasta) experienced significantly higher peaks in both blood sugar and insulin, followed by a drop in blood sugar to below baseline levels. As blood sugar and insulin are powerful metabolic regulators of both appetite and fat deposition, it would seem to follow that food processing can alter the extent to which a given food is "fattening." Indeed, a substantial scientific literature now supports this claim (Taubes, 2007). The "glycemic effect" is just one way in which processed foods can have a direct effect on appetite and calorie intake; it is also well known, for example, that sugar, salt, and other food additives directly target the brain's reward pathways in a way that stimulates shortterm food intake (Isganaitis and Lustig, 2005; Smith and Tasnádi, 2007) and probably long-term habit formation.

A deeper understanding of the hormonal regulation of energy in the human body has led some experts to declare that rather than being a problem of energy imbalance, obesity is best viewed as problem of excessive energy deposition (e.g., Lustig, 2013). In other words, all calories are not created equal, and some foods may be "fattening" even when eaten in moderation.

\section{Message 2: Exercise More}

Consistent with the "counting calories" message, industry spokespeople often lament the role of sedentary lifestyles in exacerbating the obesity problem. The website of the Center for Consumer Freedom $(\mathrm{CCF})^{5}$, for example, under the heading "The Truth about

${ }^{5} \mathrm{CCF}$ is the food-industry-funded "grassroots" organization that once launched a $\$ 600,000$ rapid-response ad campaign trumpeting the news that U.S. obesity-related mortality rates were lower than previously thought (Simon, 2006). 
the Obesity Debate," declares that sound scientific evidence points to lack of physical activity as the primary cause of obesity. Only one of the subsequent bullet points, however, links to a study that even makes this claim. In it, the authors do indeed describe a large longitudinal study of adolescent girls in which decreases in reported physical activity (but not changes in reported calorie intake) tracked increases in body mass index over time (Kimm et al., 2005). The authors (but not the CCF website) are quick to point out, however, that calorie intake is often under-reported among adolescent girls, and that this under-reporting is known to increase with age. Left unmentioned by CCF are the handful of careful studies that have shown the raw associations between obesity and sedentary lifestyles to be spurious (Cawley et al., 2007, 2006; Eid et al., 2008). ${ }^{6}$

In fact, there remains a great deal of uncertainty as to the cause(s) of the obesity epidemic. It may be that physical activity has played an important role, but the evidence remains weak, and there are many other candidate causes (McAllister et al., 2009; Smith, 2012). The widespread consumption of industrially processed foods should be high on the list.

\section{Message 3: Let Consumers Choose}

Taxes or other restrictions on today's mass-marketed foods, according to the industry view, would represent a reprehensible imposition on the rights of the sovereign consumer; the industry only produces what consumers demand, after all. The model we present above offers a direct refutation of this argument: Yes, consumers may be purchasing mass-produced convenience foods in ever-increasing numbers, but they do so in a world of imperfect information, in which the sellers of these foods have influenced the nature of the information on which their decisions are based.

${ }^{6}$ One notable exception to this dearth of evidence is Cawley et al. (2013), who report a negative effect of physical education on body mass index for $5^{\text {th }}$-grade boys, but not for other age groups. The effect was also less pronounced in girls, who evidently are more likely to decrease after-school activity when inschool physical education increases. 
Our objection to the "consumer choice" assertion carries more weight, however if our model is not taken too literally. There is a large body of scientific evidence showing that dietary choice - or perhaps more properly: dietary behavior - is a function of social setting, of stress, of emotional state, of habit, and of attachment to colorful product logos, among other things (Oliver et al., 2000; Smith, 2004). Many of these phenomena are consistent with our formal model, but only if one admits an "as-if" optimization perspective (as is our wont). Promotional campaigns, for instance, might use emotionally charged imagery to stimulate demand and increase brand loyalty. Consumer responsiveness to such campaigns might seem to fall outside the realm of rational choice, but it is nevertheless possible to interpret such a demand shift as resulting from adjusting consumer perceptions about the value of the product.

\section{Conclusion}

In April 2005, the USDA released a new version of its "Food Guide Pyramid," the iconic educational tool used to teach school children about what constitutes a healthy diet. Unlike previous editions, this one was not dominated by pictures of foods, but instead "MyPyramid" was made up of a colorful triangular rainbow with a stick figure energetically stair-stepping up the side. The main innovation in the new program, aside from the colorful graphic, was a new website, www.mypyramid.gov, where children would find online tools to help them calculate how many calories are in the various foods they eat. Critics were quick to note the echoes of industry messaging embedded in MyPyramid, and that the job of crafting the message had been contracted out to public relations firm Porter Novelli, whose clients have included McDonald's and the Snack Food Association (Simon, 2006). MyPyramid has been widely adopted in schools as a tool in teaching about diet and health (Peregrin, 2006). ${ }^{7}$

Our interpretation of food industry practice as the manifestation of profit

\footnotetext{
${ }^{7}$ MyPyramid.gov was replaced in 2011 with MyPlate.gov, which—while dropping the stair steps from the main graphic — maintains an emphasis on physical activity and calorie counts.
} 
maximizing behavior in the presence of rational (but uniformed) consumers is likely to seem novel to public health advocates and deep capture theorists outside the field of economics. These groups have tended to emphasize instances of outright deception and consumer susceptibility to psychological manipulation in their descriptions of the phenomena discussed here. We are inclined to think that the formal economic theory we offer provides a more direct framework for understanding the underlying incentives and parameters at work in deep capture, and thus is likely to provide greater clarity to policymakers seeking to understand the nature of the obesity debate.

Academic research and discussions of policy implication necessarily take place within the context of our larger society, and it would be foolish to think that the strenuous efforts of the food industry to influence public perceptions of obesity do not affect academics. It has long been known, however, that a campaign aimed at swaying the public is often most effective when the commercial or political motives of the instigator remain concealed (Bernays, 1928). It is our hope that a better understanding of the strategic considerations at play in today's obesity debate will lead to more and better research and, ultimately, a healthier populace. 


\section{References}

Batada, A., Seitz, M.D., Wootan, M.G., Story, M., 2008. Nine out of 10 Food Advertisements Shown During Saturday Morning Children's Television Programming Are for Foods High in Fat, Sodium, or Added Sugars, or Low in Nutrients. J. Am. Diet. Assoc. 108, 673-678.

Benforado, A., Hanson, J., Yosifon, D., 2004. Broken Scales: Obesity and Justice in America. Emory J 1645.

Bernays, E.L., 1928. Propaganda. Routledge.

Bó, E.D., 2006. Regulatory Capture: A Review. Oxf. Rev. Econ. Policy 22, 203-225.

Brownell, K.D., Horgen, K.B., 2004. Food fight: The inside story of the food industry, America's obesity crisis, and what we can do about it. Contemporary books Chicago.

Cawley, J., Frisvold, D., Meyerhoefer, C., 2013. The impact of physical education on obesity among elementary school children. J. Health Econ. 32, 743-755.

Cawley, J., Meyerhoefer, C., Newhouse, D., 2006. Not Your Father's PE: Obesity, Exercise, and the Role of Schools. Educ. 6, 60-66.

Cawley, J., Meyerhoefer, C., Newhouse, D., 2007. The impact of state physical education requirements on youth physical activity and overweight. Health Econ. 16, 12871301.

Chou, S.-Y., Grossman, M., Saffer, H., 2004. An Economic Analysis of Obesity: Results from the Behavioral Risk Factor Surveillance System. J. Health Econ. 23, 565587.

Croley, S.P., 2007. Regulation and public interests: The possibility of good regulatory 
government. Princeton University Press.

Darby, M.R., Karni, E., 1973. Free Competition and the Optimal Amount of Fraud. J. Law Econ. 16, 67-88.

Eid, J., Overman, H.G., Puga, D., Turner, M.A., 2008. Fat city: Questioning the relationship between urban sprawl and obesity. J. Urban Econ. 63, 385-404.

Granfeldt, Y., Bjorck, I., Hagander, B., 1991. On the importance of processing conditions, product thickness, and egg addition for the glycemic and hormonal responses to pasta-A comparison with bread made from pasta ingredients. Eur. J. Clin. Nutr. 45, 489-499.

Hanson, J., Yosifon, D., 2003. The Situation: An Introduction to the Situational Character, Critical Realism, Power Economics, and Deep Capture. U Pa Rev 152, 129.

Hanson, J., Yosifon, D., 2004. The Situational Character: A Critical Realist Perspective on the Human Animal. Georgetown Law J. 93, 1-179.

Isganaitis, E., Lustig, R., 2005. Fast food, central nervous system insulin resistance, and obesity. Arterioscler. Thromb. Vasc. Biol. 25, 2451-2462.

Iuliano, J., 2010. Killing Us Sweetly: How to Take Industry out of the FDA. J. Food Law Policy 6, 31 .

Jacobson, M., 2005. Liquid candy: How Soft Drinks Are Harming America's Health. Center for Science in the Public Interest, Washington, DC.

Kimm, S.Y., Glynn, N.W., Obarzanek, E., Kriska, A.M., Daniels, S.R., Barton, B.A., Liu, K., 2005. Relation between the changes in physical activity and body-mass index during adolescence: a multicentre longitudinal study. The Lancet 366, 301-307.

Kotz, K., Story, M., 1994. Food advertisements during children's Saturday morning television programming: are they consistent with dietary recommendations? J. 
Am. Diet. Assoc. 94, 1296-1300.

Laffont, J.-J., Tirole, J., 1993. A theory of incentives in procurement and regulation. MIT Press, Cambridge, Mass.

Lustig, R.H., 2013. Fat chance: beating the odds against sugar, processed food, obesity, and disease. Hudson Street Press, New York, New York.

McAllister, E.J., Dhurandhar, N.V., Keith, S.W., Aronne, L.J., Barger, J., Baskin, M., Benca, R.M., Biggio, J., Boggiano, M.M., Eisenmann, J.C., Elobeid, M., Fontaine, K.R., Gluckman, P., Hanlon, E.C., Katzmarzyk, P., Pietrobelli, A., Redden, D.T., Ruden, D.M., Wang, C., Waterland, R.A., Wright, S.M., Allison, D.B., 2009. Ten Putative Contributors to the Obesity Epidemic. Crit. Rev. Food Sci. Nutr. 49, 868-913.

Oliver, G., Wardle, J., Gibson, E.L., 2000. Stress and Food Choice: A Laboratory Study. Psychosom. Med. 62, 853-865.

Peregrin, T., 2006. Making MyPyramid for Kids a Successful Tool in Nutrition Education. J. Am. Diet. Assoc. 106, 656-658.

Salatin, J., 2007. Everything I want to do is illegal. Polyface, Swoope, Va.

Simon, M., 2006. Appetite for Profit: How the Food Industry Undermines our Health and How to Fight Back. Nation Books, New York.

Smith, T.G., 2004. The McDonald's Equilibrium: Advertising, Empty Calories, and the Endogenous Determination of Dietary Preferences. Soc. Choice Welf. 23, 383413.

Smith, T.G., 2012. Review of Obesity and the Economics of Prevention: Fit Not Fat. Am. J. Agric. Econ. 94, 815-817.

Smith, T.G., Chouinard, H.H., Wandschneider, P.R., 2011. Waiting for the invisible hand: 
Novel products and the role of information in the modern market for food. Food Policy 36, 239-249.

Smith, T.G., Tasnádi, A., 2007. A Theory of Natural Addiction. Games Econ. Behav. 59, 316-344.

Stigler, G.J., 1971. The Theory of Economic Regulation. Bell J. Econ. Manag. Sci. 2, 321.

Stivers, A.E., 2009. Regulating Market Language: Market Failure in Descriptive Signals. J. Consum. Policy 32, 23-41.

Taubes, G., 2007. Good Calories, Bad Calories: Challenging the Conventional Wisdom on Diet, Weight Control, and Disease. Alfred A. Knopf, New York.

Teisl, M.F., Roe, B., 1998. The Economics of Labeling: An Overview of Issues for Health and Environmental Disclosure. Agric. Resour. Econ. Rev. 27, 140-150.

Tirole, J., 1986. Hierarchies and Bureaucracies: On the Role of Collusion in Organizations. J. Law Econ. Organ. 2, 181-214.

Verbeke, W., 2005. Agriculture and the food industry in the information age. Eur. Rev. Agric. Econ. 32, 347-368.

Weitzman, M.L., 1979. Optimal Search for the Best Alternative. Econometrica 47, 641654.

Yosifon, D.G., 2006. Resisting Deep Capture: The Commercial Speech Doctrine and Junk-Food Advertising to Children. Loyola Los Angeles Law Rev. 39, 507. 